\title{
A CELL SHRINKAGE ARTEFACT IN GROWTH PLATE CHONDROCYTES WITH COMMON FIXATIVE SOLUTIONS: IMPORTANCE OF FIXATIVE OSMOLARITY FOR MAINTAINING MORPHOLOGY
}

\author{
Mohamad Y. Loqman¹, Peter G. Bush², Colin Farquharson³, and Andrew C. Hall ${ }^{1}$ \\ ${ }^{1}$ Centre for Integrative Physiology, School of Biomedical Sciences, George Square, University of Edinburgh, \\ Edinburgh EH8 9XD, Scotland, UK \\ ${ }^{2}$ School of Pharmacy and Biomolecular Sciences, University of Brighton, Lewes Road, Brighton, BN2 4GJ, \\ England, UK \\ ${ }^{3}$ The Roslin Institute, R(D)SVS, Developmental Biology, University of Edinburgh, Roslin EH25 9PS, Scotland, UK
}

\begin{abstract}
The remarkable increase in chondrocyte volume is a major determinant in the longitudinal growth of mammalian bones. To permit a detailed morphological study of hypertrophic chondrocytes using standard histological techniques, the preservation of normal chondrocyte morphology is essential. We noticed that during fixation of growth plates with conventional fixative solutions, there was a marked morphological (shrinkage) artifact, and we postulated that this arose from the hyper-osmotic nature of these solutions. To test this, we fixed proximal tibia growth plates of 7-day-old rat bones in either (a) paraformaldehyde (PFA; 4\%), (b) glutaraldehyde (GA; 2\%) with PFA (2\%) with ruthenium hexamine trichloride (RHT; 0.7\%), (c) GA ( $2 \%)$ with RHT $(0.7 \%)$, or (d) GA $(1.3 \%)$ with RHT $(0.5 \%)$ and osmolarity adjusted to a 'physiological' level of $\sim 280 \mathrm{mOsm}$. Using conventional histological methods, confocal microscopy, and image analysis on fluorescentlylabelled fixed and living chondrocytes, we then quantified the extent of cell shrinkage and volume change. Our data showed that the high osmolarity of conventional fixatives caused a shrinkage artefact to chondrocytes. This was particularly evident when whole bones were fixed, but could be markedly reduced if bones were sagittally bisected prior to fixation. The shrinkage artefact could be avoided by adjusting the osmolarity of the fixatives to the osmotic pressure of normal extracellular fluids ( $280 \mathrm{mOsm})$. These results emphasize the importance of fixative osmolarity, in order to accurately preserve the normal volume/morphology of cells within tissues.
\end{abstract}

Keywords: Shrinkage, artefact, osmolarity, glutaraldehyde, para-formaldehyde, growth plate.

*Address for correspondence:

Andrew C. Hall

Centre for Integrative Physiology

School of Biomedical Sciences

University of Edinburgh

Hugh Robson Building

George Square, Edinburgh EH8 9XD

Scotland, United Kingdom

Telephone Number: + 44 (0)131650 3263

FAX Number: + $44(0) 1316502872$

E-mail: a.hall@ed.ac.uk

\section{Introduction}

The accurate study of the morphology of living cells as they appear within tissues is difficult but fundamental for an understanding of normal cell biology, and the changes that occur in disease states. Accordingly a vast amount of research has been performed on chemically-fixed cells and tissues. The intention has been to retain the fine morphology and constituents of living in situ cells so that they can be studied without the complications of deleterious changes to cell metabolism and loss of viability during the investigation (see Hopwood, 1985). In addition, tissue fixation should protect against cell autolysis, attack by bacteria, and changes to cell volume and shape especially during subsequent preparative treatment (Baker, 1960) when tissue dehydration is frequently performed. Thus, fixative solutions should serve to stabilize the specimen and protect it from rigorous physical tissue processing and staining as required for study (Hopwood, 1969). Our particular research emphasis has been on the cellular mechanisms underlying the structure and function of the mammalian growth plate. There has been extensive study on chemically-fixed growth plates, and particular interest in the remarkable increase in chondrocyte volume which is a major determinant of bone growth (Breur et al., 1991). The large volumes of growth plate chondrocytes (typically ranging from 1,000 to $10,000 \mu \mathrm{m}^{3}$; Bush et al., 2008) potentially makes them extremely sensitive to osmotic artefacts during fixation.

Para-formaldehyde (PFA) and glutaraldehyde (GA) and their combinations have long been used as fixative solutions (Fox et al., 1985; Hopwood, 1969) to retain the properties of cells and tissues (Kiernan, 1999; Renshaw, 2007). Perhaps the most widely used fixative for histology and histopathology is $10 \%$ neutral buffered formalin however this is not usually used for studies on the growth plate. Examples of more conventional aldehyde preparations used for this tissue are (a) 4\% (w/v) PFA (Fox et al., 1985; Hosoya et al., 2005; solution A, Table 1) which has the same formaldehyde concentration (4\%) as $10 \%$ Formalin (Kiernan, 1999), (b) 2\% (w/v) GA \& RHT (ruthenium hexamine trichloride) combined with 2\% (w/v) PFA (Farnum et al., 2002; solution B, Table 1) and (c) $2 \% \mathrm{GA}(\mathrm{w} / \mathrm{v})$ with $0.7 \%(\mathrm{w} / \mathrm{v})$ RHT (Hunziker et al., 1983; solution $\mathrm{C}$ see Table 1). Although the fixative properties have been widely known, less appreciated is the fact that the osmolarity of these solutions is markedly greater than that of typical physiological extracellular 
solutions (Table 1). The osmolarity of the fixative solutions and their effects on cell and tissue morphology have received relatively little attention recently - indeed often appear ignored - despite the fact that there are studies in the literature highlighting this issue. For example, Schultz and Karlsson (1965) observed that hypertonic fixative solutions perfused into the central nervous system caused cellular shrinkage and increased extracellular spaces, whereas isotonic (300-320mOsm) and hypotonic fixatives could result in cell swelling. Mathieu et al. (1978) have reported the importance of both the \% of GA and the molarity of the vehicle used for the fixative solution for the preservation of lung tissue. Even with these early studies, there are recent examples of investigators using hyper-osmolar fixative solutions (Farnum et al., 2002; Hosoya et al., 2005) but little if any comment on the morphology of the fixed cells which frequently appear shrunken/distorted (Erben, 1997; Kouri et al., 1996; Ross and Reith, 1985; Sanchez et al., 2000; Van der Eerden et al., 2000) and little or no attempt at quantification of the shrinkage artefact. We wished therefore (a) to re-visit this issue and emphasize the importance of osmotic correction to fixative solutions in order to retain cell morphology and (b) provide quantitative data on the extent of cell shrinkage and specifically report on the influence of fixative osmolarity on connective tissue cells.

During preliminary experiments attempting to optimize the fixation protocols for mammalian growth plates, we noticed that for the same standard fixative, the appearance of hypertrophic zone cells in histological sections from whole bones were markedly different compared to those from sagittally sectioned bones. The morphology of the cells in the whole bone fixed samples appeared considerably mis-shapen and shrunken, whereas in the bisected bone, morphology was relatively normal. From our previous studies on the shape/volume of chondrocytes exposed to osmotic challenge (Bush and Hall, 2001) we suspected that an artefact of the relatively high osmotic pressure of the fixative solutions might account for the abnormal chondrocyte morphology.

Thus, in the present study, we further examined using standard and modified fixative solutions, these shrinkage artefacts. By quantifying the osmotic shrinkage effect on hypertrophic growth plate chondrocytes, the data confirmed our preliminary observations that whole bones were particularly sensitive compared to those sagittally bisected prior to fixation. We also demonstrate that adjusting the fixative solution to an osmolarity close to that of typical extracellular solutions (approx. 280mOsm; solution D, Table 1) abolishes this artefact.

\section{Materials and Methods}

\section{Biochemicals and solutions}

Unless otherwise stated, all biochemicals and solutions were purchased from Sigma-Aldrich (Poole, U.K.) RHT was purchased from Polysciences Inc. (Warrington, PA, U.S.A.). Glutaraldehyde was of a grade suitable for electron microscopy. Paraformaldehyde solution was prepared from paraformaldehyde powder (purity of $\geq 95 \%$ ). The fluorescent cytoplasmic labelling dye, chloromethylfluorescein diacetate CMFDA (CellTracker ${ }^{\mathrm{TM}}$ Green) and calcein AM were obtained from Invitrogen (Paisley, U.K.) and the mounting medium, FluorSave ${ }^{\mathrm{TM}}$ was purchased from Calbiochem (Nottingham, U.K.) Sodium cacodylate buffer was prepared by dissolving sodium cacodylate trihydrate powder (assay, approx. 98\%) in distilled water, and the $\mathrm{pH}$ was corrected to 7.4 by addition of $\mathrm{HCl}$.

\section{Animals and growth plate preparation}

Sprague-Dawley rats (7-day-old; P7) were humanely killed for other experiments following U.K. Home Office guidelines. The tibia of each hind limb with intact proximal growth plate cartilage was dissected and temporarily placed in medium (phosphate buffered saline; PBS; approx. 293 mOsm) containing alpha modified essential medium $(\alpha-\mathrm{MEM} ; 7.5 \% \mathrm{v} / \mathrm{v}$; Invitrogen) and bovine serum albumin $\mathrm{V}(1 \mathrm{mM})$, prior to fixation.

For the preparation of samples for histology, 2 tibia from each animal were used and placed in fixative solutions of differing composition as follows: (a) conventional fixative solutions (Table 1), (b) fixatives with GA concentration maintained constant, but with various osmolarities similar to those used for conventional fixative solutions (Table 2), and (c) fixatives with various concentrations of GA but with osmolarity maintained at approx. 550mOsm (Table 3). The growth plates were fixed for $24 \mathrm{hrs}$ at room temperature for subsequent paraffin-

Table 1. Composition of fixative solutions used in the study.

\begin{tabular}{|c|c|c|c|c|c|}
\hline $\begin{array}{c}\text { Solution } \\
\text { ID }\end{array}$ & Fixative solution & $\begin{array}{c}\text { Cacodylate } \\
\text { buffer } \\
\mathbf{( m M )}\end{array}$ & pH & $\begin{array}{c}\text { Osmolarity } \\
\mathbf{( m O s m )}\end{array}$ & References \\
\hline A & PFA 4\% & None & 7.11 & $1148 \pm 2$ & Hosoya et al., 2005 \\
\hline B & PFA 2\%+ GA 2\% + RHT 0.7\% & 100 & 7.06 & $1135 \pm 32$ & Farnum et al., 2002 \\
\hline C & GA 2\% + RHT 0.7\% & 50 & 6.72 & $420 \pm 20$ & Hunziker et al., 1983 \\
\hline D & GA 1.3\%+RHT 0.5\% & 30 & 5.67 & $270 \pm 10$ & (present study) \\
\hline
\end{tabular}

Fixative solutions were prepared as described in the references cited which reported the morphology of growth plate chondrocytes following fixation. For solution A, distilled water was used instead of cacodylate buffer. Fixative solution $\mathrm{D}$ was prepared by diluting solution $\mathrm{C}$ with distilled water. [Concentrations are given as $\%(\mathrm{v} / \mathrm{v})$ for GA= glutaraldehyde and $\mathrm{PFA}=$ paraformaldehyde, and as $\%(\mathrm{w} / \mathrm{v})$ for $\mathrm{RHT}=$ ruthenium hexamine trichloride]. 
Table 2. Modified fixative solutions with constant concentrations of GA and RHT, but with osmolarity varied using $\mathrm{NaCl}$.

\begin{tabular}{|c|c|c|c|c|}
\hline $\begin{array}{c}\text { Solution } \\
\text { ID }\end{array}$ & Fixative Solution & $\begin{array}{c}\text { Cacodylate buffer } \\
(\mathbf{m M}) \mathbf{p H ~ 7 . 4}\end{array}$ & $\mathbf{p H}$ & $\begin{array}{c}\text { Osmolarity } \\
\text { (mOsm) }\end{array}$ \\
\hline $\mathbf{2 8 0}$ & $0.7 \%$ RHT $+1 \%$ GA & 50 & 6.76 & $273 \pm 13$ \\
\hline $\mathbf{4 8 0}$ & $0.7 \%$ RHT $+1 \%$ GA & 50 & 6.60 & $467 \pm 28$ \\
\hline $\mathbf{6 4 0}$ & $0.7 \%$ RHT $+1 \%$ GA & 50 & 6.55 & $637 \pm 20$ \\
\hline $\mathbf{1 2 0 0}$ & $0.7 \%$ RHT $+1 \%$ GA & 50 & 6.49 & $1141 \pm 116$ \\
\hline
\end{tabular}

Fixative solutions were prepared with the constituents at the concentrations indicated (see Materials and Methods), with the osmolarities and $\mathrm{pH}$ of the resulting solutions as shown. Concentrations are given as \% (w/v) for RHT, and $\%(\mathrm{v} / \mathrm{v})$ for GA. Data expressed as means \pm S.E.M. from at least 3 independent determinations.

Table 3. Modified fixative solutions with varying GA concentration, but with similar final osmolarity.

\begin{tabular}{|c|c|c|c|c|c|}
\hline $\begin{array}{c}\text { Solution } \\
\text { ID }\end{array}$ & Fixatives & $\begin{array}{c}\text { Glutaraldehyde } \\
\text { concentration (\%) }\end{array}$ & $\begin{array}{c}\text { Cacodylate buffer } \\
\text { (mM), pH 7.4 }\end{array}$ & pH & $\begin{array}{c}\text { Osmolarity } \\
\text { (mOsm) }\end{array}$ \\
\hline 0.5GA & $0.7 \%$ RHT + GA & 0.5 & 50 & 6.81 & $543 \pm 1$ \\
\hline 1GA & $0.7 \%$ RHT + GA & 1.0 & 50 & 6.73 & $542 \pm 4$ \\
\hline 2GA & $0.7 \%$ RHT + GA & 2.0 & 50 & 6.72 & $556 \pm 18$ \\
\hline 4GA & $0.7 \%$ RHT + GA & 4.0 & 50 & 6.35 & $577 \pm 11$ \\
\hline
\end{tabular}

Fixative solutions were prepared with the constituents including different GA concentrations ( $\% \mathrm{v} / \mathrm{v})$ as indicated (see Materials and Methods), with the osmolarities of the resulting solutions as shown. Concentrations of RHT are given as $\%(\mathrm{v} / \mathrm{v})$. Data expressed as means \pm S.E.M from at least 3 independent determinations.

embedding for histological sectioning. For group (a) three intact tibias and 3 bisected tibias were fixed in each fixative solution, whereas in group (b) and (c), three and five intact tibias were used in each fixative solution respectively.

For the preparation of growth plates for the analysis of in situ growth plate chondrocyte (GPC) volume, tibias from eight $\mathrm{P} 7$ rat pups were grouped into: (i) five bones maintained intact, and (ii) ten bones that were bisected sagittally. Bones were incubated with either CMFDA-green for 60mins (if the bones were subsequently fixed) or calcein AM (for non-fixed bones). Then, all bones from group (i) and four bones from group (ii) were fixed in solution A. Three bones from group (ii) were fixed in osmoticallycorrected fixative solution (solution D, Table 1). When appropriate, bones were fixed for $24 \mathrm{hrs}$ at room temperature. The remaining 3 bones from group (ii) were maintained unfixed for in situ living cell imaging. The osmolarity of all solutions was determined using a freezing point micro-osmometer (Model 3300, Vitech Scientific Ltd., Partridge Green, U.K.) with solid $\mathrm{NaCl}$ or distilled water added to adjust the osmolarity to the required range. The $\mathrm{pH}$ of all solutions was measured at room temperature using a SevenEasy ${ }^{\mathrm{TM}} \mathrm{pH}$ meter (Mettler Toledo, UK) with the $\mathrm{pH}$ of fixative solutions altered by adding either $\mathrm{HCl}$ or $\mathrm{NaOH}$.

\section{Histology of the growth plate}

Bones were embedded in paraffin wax using a standard procedure (Kiernan, 1999) and tissue sections $(10 \mu \mathrm{m})$ cut using a microtome (Reichert-Jung Microtome 2050 Supercut, Arnsberg, Germany). The sections were then mounted on poly-l-lysine-coated microscope slides (Polysine $^{\mathrm{TM}}$, VWR International, Leicestershire, UK) and dried overnight. After de-paraffinisation with xylene and rehydration with a series of ethanol solutions $(100 \%, 90 \%$, $75 \%$ ), the sections were stained with $0.1 \%(\mathrm{w} / \mathrm{v})$ Toluidine blue O in PBS buffer ( $\mathrm{pH} 5.5 ; 30$ secs at room temperature) using the technique adapted from Bancroft and Cook (1994). The sections were then rinsed briefly in distilled water and allowed to air dry prior to mounting in FluorSave $^{\mathrm{TM}}$ with cover slips.

Measurement of growth plate chondrocyte shrinkage Histological sections of fixed hypertrophic GPC stained with $0.1 \%$ Toluidine blue $\mathrm{O}$ were observed under an $\mathrm{x} 63$ (oil-immersion) objective lens. Several histological views of chondrocytes within sections S5 and S6 of the hypertrophic zone (see details in the section 'In situ volume measurement' (below), and Figure 1(A)) were randomly selected and the images recorded using a mounted digital camera (Coolpix 4500, Nikon, Tokyo, Japan) with Coolpix MDC2 Relay lens (MXA 2900, Nikon). The captured images were then transferred to a computer for further image analysis. Java-based scientific image processing software (ImageJ, NIH, Bethesda, MD, U.S.A.) was then used to measure the cell shrinkage from the images of the histological sections.

In order to determine the extent of chondrocyte shrinkage it was necessary to identify the area of individual chondrocytes and that of their lacuna - i.e., the 'cavity' in which the cell resided. It was in fact relatively straightforward to do this as the outermost edge of the cell area stained distinctly with Toluidine blue $\mathrm{O}$, and the perimeter of the corresponding lacuna was identified as the edge of the extracellular matrix that demarcated the border between the stained area of the matrix and the 'space' of the lacuna which was relatively unstained. It was noted that the area of the lacuna could only be observed if there was cell shrinkage. For each group of treatments, 4 fields of view from each growth plate section were selected and up to 11 cells and their corresponding lacunae randomly taken for area measurement. The area of each 
A.

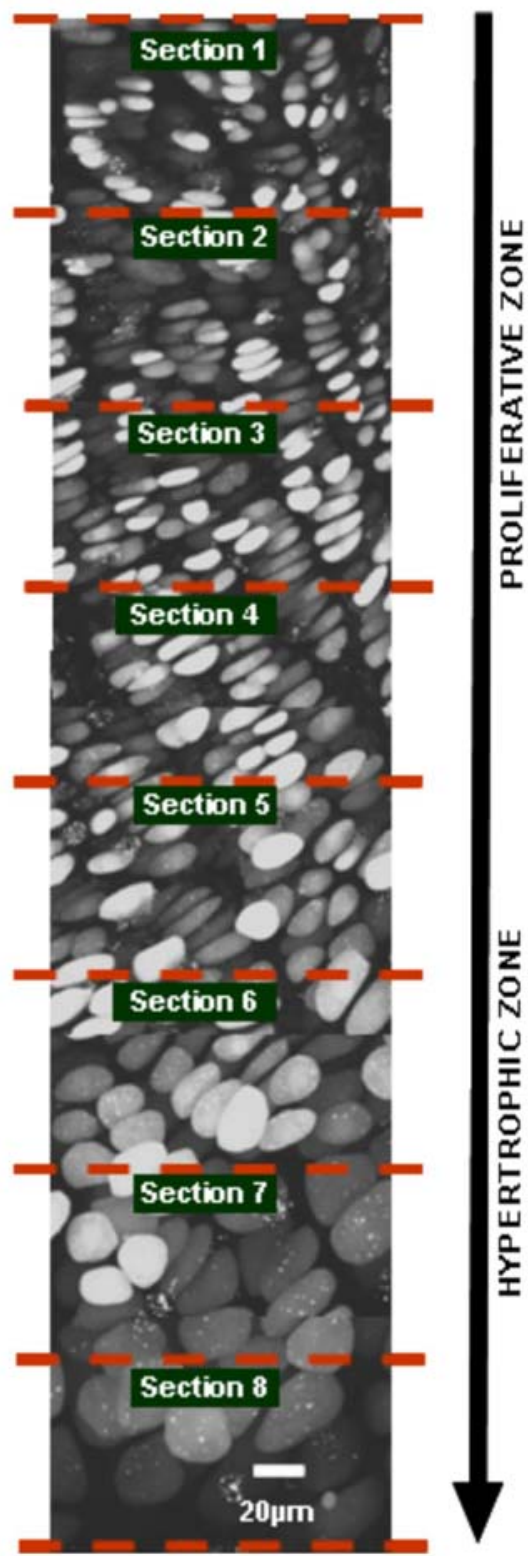

B.

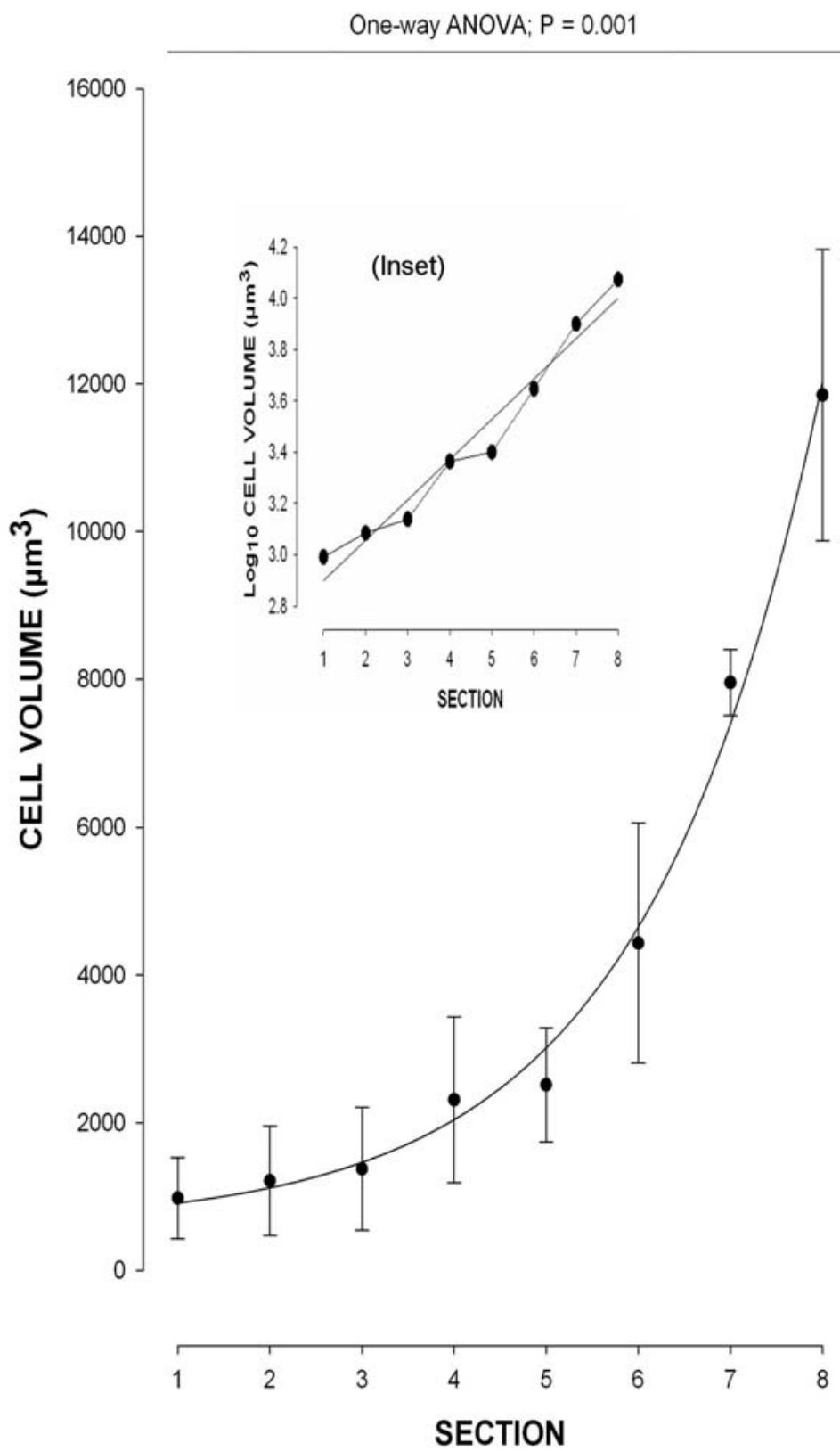

Fig. 1. Overview of the rat growth plate, and division of in situ living rat chondrocytes (GPC) into sections from proliferative to hypertrophic zones. Living chondrocytes in a bisected proximal tibia of a 7-day-old rat pup were labelled with calcein AM, and sequential CLSM images taken with a x63 water-dipping objective (see Materials and Methods). Panel (A) demonstrates the projected image of a section of the growth plate showing the increase in chondrocyte volume from proliferative to hypertrophic zone. The zones were divided into eight equal sections (labelled S1-S8) from early proliferative zone to late hypertrophic zone. Panel (B) shows the changes in the volume along the growth plate sections as measured using Volocity ${ }^{\circledR}$ software on living in situ growth plate chondrocyte images captured with CLSM. Also shown is an inset where the same data points were transformed to $\log _{10}$. (Data shown are means \pm S.E.M. or S.D. as appropriate, with $\mathrm{n}=2$ for S1-S4 and S7-S8, and $\mathrm{n}=3$ for S5-S6; and at least $\mathrm{N}=15$ cells measured at each section).

cell and that of its associated lacuna were selected by outlining their perimeters using the freehand selection tool (see Fig. 2A, panel a). The total area of the cell and its lacuna were then determined using the 'analyze' and 'measure' toolbar in the software. Cell shrinkage was calculated as $\{100-[($ cell area/lacuna area $) \times 100]\}$ and expressed as a percentage of the initial volume (see Fig. 2A, panel a). When the cell and its corresponding lacuna shared the same perimeter, the value of cell shrinkage was zero as defined above.

\section{Confocal laser scanning microscopy (CLSM)}

An upright Zeiss Axioskop LSM 510 (Carl Zeiss Ltd., Welwyn Garden City, Herts., U.K.) CLSM was used to acquire fluorescent images of in situ hypertrophic growth plate chondrocytes. Cells were visualized using a Plan- 

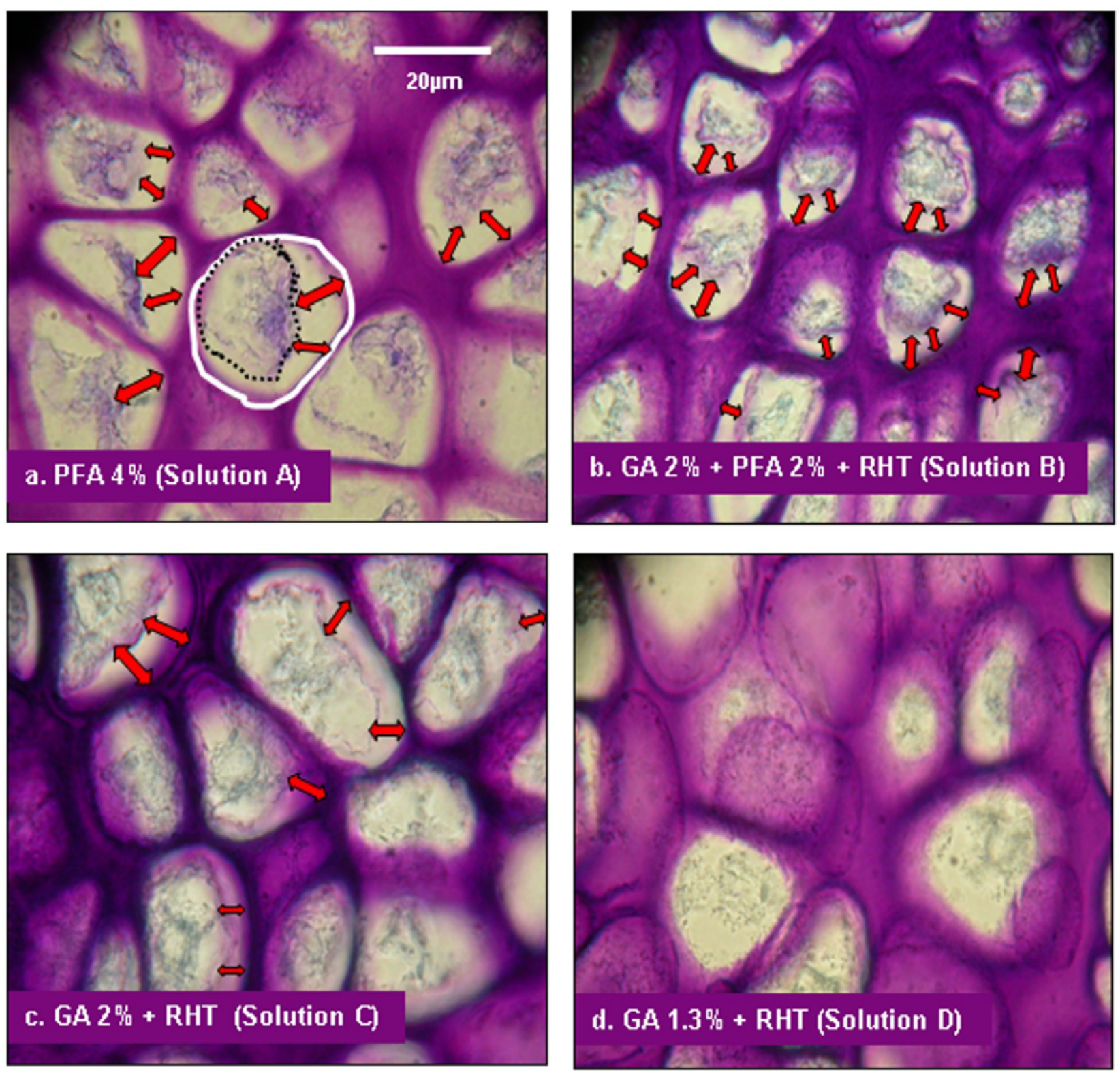

Fig. 2A. Conventional fixatives cause considerable shrinkage of hypertrophic growth plate chondrocytes when applied to whole (intact) bones. Intact proximal tibias of 7-day-old rat pups were fixed using various standard fixative solutions (Table 1) and sections prepared and stained with $0.1 \%$ Toluidine blue $\mathrm{O}$ (see Materials and Methods). The method used to calculate the extent of chondrocyte shrinkage was illustrated in Panel (a). The thick white line was drawn free-hand around the perimeter of the lacuna and the black broken line drawn around the membrane edge of its resident chondrocyte (see details in Materials and Methods). The gap between the cells and the border of the lacuna is illustrated by double headed arrows. Cell shrinkage was observed in all conventional fixatives (panels a - c) but not when the osmolarity of the fixative was adjusted to a 'physiological' osmolarity (panel d). For pooled data see Figure 3. The scale bar of $20 \mu \mathrm{m}$ in this and the following Figure applied to all panels.

Neofluar x10/0.3 numerical aperture (NA) dry objective for a low power overview and an Achroplan x 63/0.95 NA ceramic water-dipping lens for high power views. Intracellular CMFDA was excited using an Argon laser $(\mathrm{Ex}=488 \mathrm{~nm})$ and emitted fluorescence $(\mathrm{Em}=517 \mathrm{~nm})$ detected using a 500-550nm band pass filter. The confocal detection pinhole was set at 1.00 Airy Unit. Laser power and detector sensitivity were adjusted to provide optimum image quality. The scanning speed was typically $0.6 \mathrm{~Hz}$ with 2 frame integration of a 512 x 512 pixel image, with serial $1 \mu \mathrm{m}$ z-step optical sections (see Bush and Hall, 2001; Bush et al., 2007 for further details).

\section{In situ volume measurement}

Whole growth plates imaged from the proliferative to hypertrophic zones were divided into eight equal parts and labeled S1 to S8 (Fig. 1A). This was done so that a comparative analysis could be made between corresponding sections from different individuals irrespective of variations in section cutting angle (Bush et al., 2008). Since the greatest number of hypertrophic cells that was consistently found to be intact was in S5 and S6, the in situ growth plate cell volume analysis was performed only at these sections. Chondrocytes in S7-S8 often appeared to be in poor condition, possibly as a result of 

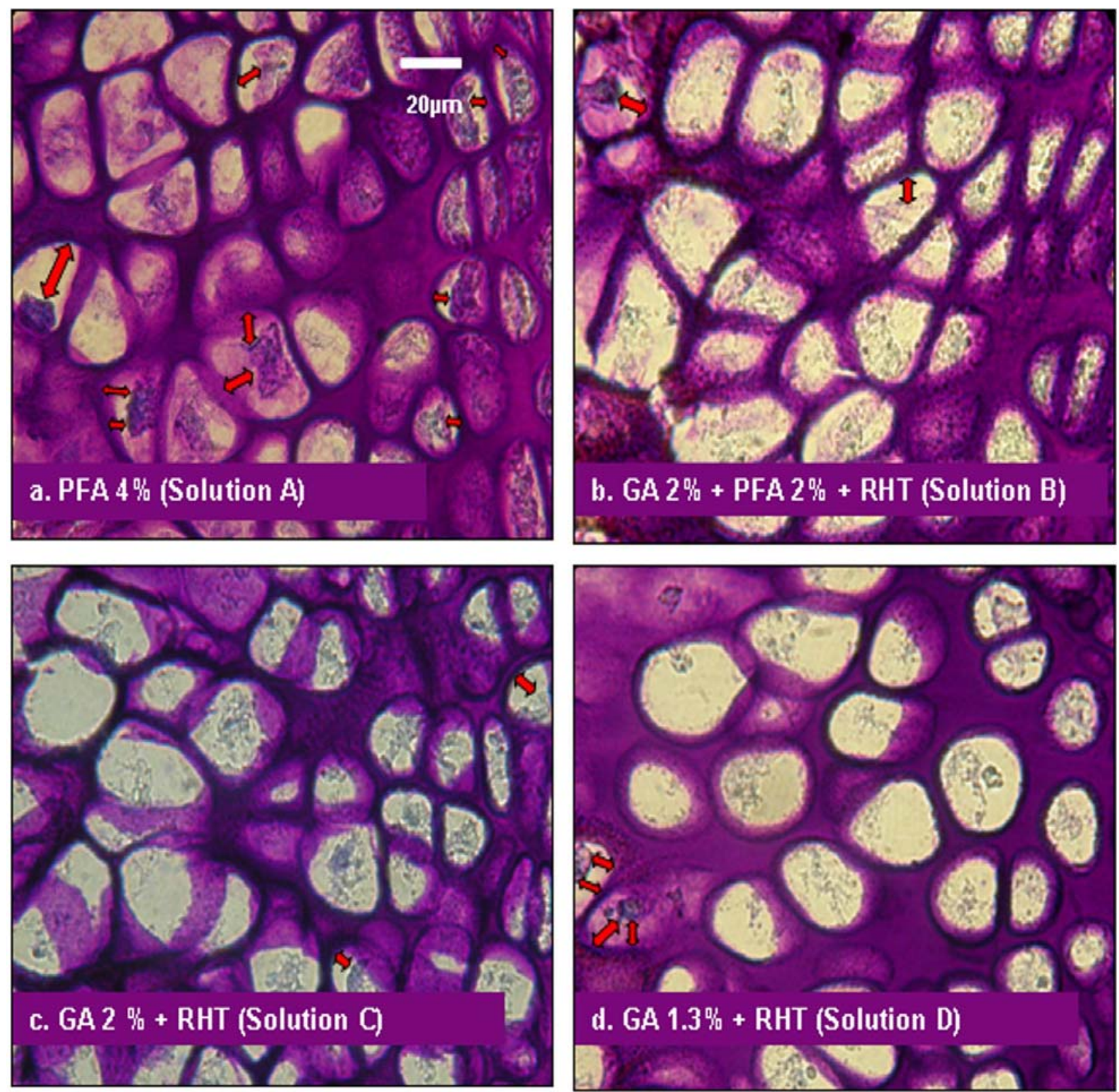

Fig. 2B. Reduced cell shrinkage in GPC of bones sagittally-bisected before fixation. Bisected sections prepared and stained with $0.1 \%$ Toluidine blue $\mathrm{O}$ (see Materials and Methods). With these bisected bones the extent of cell shrinkage was markedly less compared to the intact bones (Fig. 2A) and shrunken chondrocytes were only occasionally observed as illustrated by the double headed arrows (panel a). The morphology of chondrocytes within the three other fixative solutions (panels b to d) was relatively normal (see pooled data in Fig. 3).

cutting trauma during the preparation of the tissue (Huntley et al., 2005). Volume analysis was performed using high performance 3D imaging software (Volocity ${ }^{\circledR}$, Improvision, Coventry, U.K.) on scanned CLSM images using the calibrated cell volume method as previously described (Bush and Hall, 2001).

\section{Statistical analysis}

Data were expressed as means \pm standard error of the mean (S.E.M), obtained from a minimum of 3 separate animals $(\mathrm{n})$, and $(\mathrm{N})$ chondrocytes at each condition with the data shown as $(\mathrm{n}[\mathrm{N}])$. Statistical significance was evaluated using two-tailed Student's unpaired $t$-tests, or ANOVA tests as appropriate, with the $P$ value considered significant when $P<0.05$. Statistical tests were performed using Microsoft Office Excel (Microsoft, Redmond, WA, U.S.A.) or SigmaPlot ${ }^{\circledR}$ statistical software (Systat Software, Chicago, IL, U.S.A.).

\section{Results}

Volume and morphology of rat growth plate chondrocytes (GPC)

Initially, to determine live cell volumes and the morphology of in situ, unfixed chondrocytes, we labelled in situ growth plate chondrocytes with calcein as shown (Fig. 1). Imaging of the fluorescently-labelled in situ living growth plate chondrocytes demonstrated a clear increase in the size of GPC from the proliferative through to hypertrophic zones (Fig. 1a). Chondrocytes within the proliferative zone (between the reserve and hypertrophic zone) appeared 

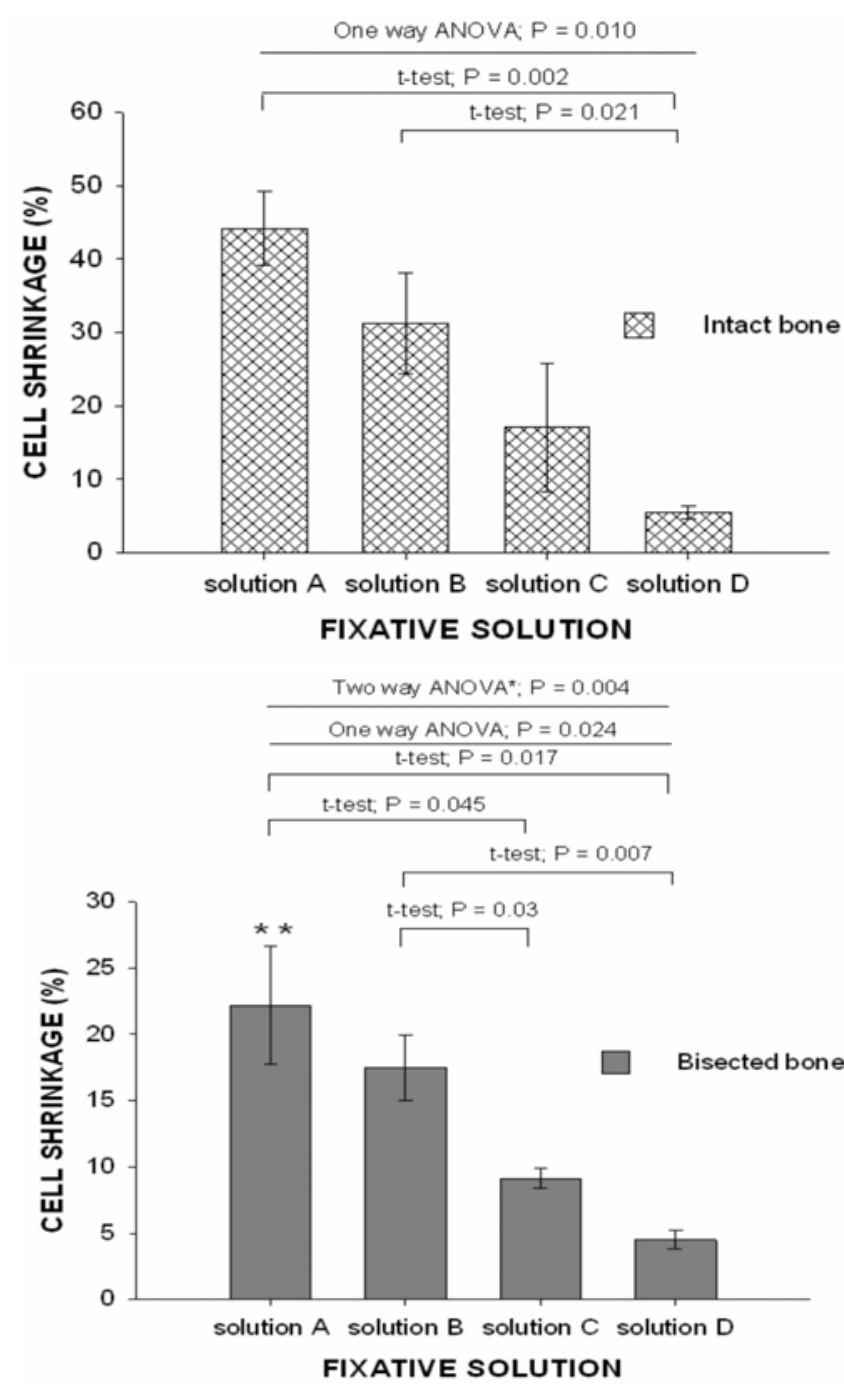

ellipsoidal and usually arranged in columns of at least three to eight cells. In the hypertrophic zone (between the proliferative zone and the zone of calcification) the cells were larger and frequently more rounded although there were cells with a height greater than the cell's width (Buckwalter et al., 1985; Farnum and Wilsman, 1986).

In accordance with the visual appearance of chondrocytes along the growth plate, the quantified volume of in situ cells increased although it was clearly not a linear process as there was a relatively poor fit to a linear regression (correlation coefficient $r^{2}=0.793$ ). The volume increase was initially gradual through to $\mathrm{S} 5$, but then became more rapid from S5-S8 similar to an exponential growth relationship (Fig. 1b). When the volume data were transformed to $\log _{10}$ and plotted semi-logarithmically (see inset to Fig. 1b) there was a much better fit to the data $\left(\mathrm{r}^{2}\right.$ $=0.955$ ) supporting the notion of a logarithmic increase in chondrocyte volume associated with hypertrophy. In the present study we focused on chondrocytes within these latter sections of the growth plate. Although the shrinkage artefact was apparent in the smaller cells, it was very difficult to quantify the phenomenon using our imaging methods (see Materials and Methods). This was because the distinction between the perimeter of the lacuna and the cell edges of smaller (shrunken) cells was difficult to determine accurately, resulting in large variations.
Fig. 3A. Growth plate chondrocyte shrinkage in histological sections from intact bones fixed in four different solutions. Cell shrinkage of in situ chondrocytes fixed in solutions A, B, C or D (for composition see Table 1) in intact tibias from 7 day-old rats were measured as described (see Materials and Methods). Data in this and the subsequent Figure were from at least (3[44]) for each condition. In this and the following Figure, $P$ values for unpaired Student's $t$-tests are shown. (Data are given as means \pm S.E.M.).

Fig. 3B. Growth plate chondrocyte shrinkage in histological sections from bisected bones fixed in four different solutions. Cell shrinkage of in situ chondrocytes fixed in solutions A, B, C or D (Table 1) in sagittally-bisected tibias from 7 day-old rats were measured as described (see Materials and Methods). A single asterisk $(*)$ denoted a significant difference when the two-way ANOVA tested the trend of cell shrinkage between intact and bisected bones in various fixative solutions. A double asterisk (**) denoted a significant difference compared to the intact bone fixed in solution A (Student's unpaired $t$-test).

Therefore, we decided to study the phenomenon only on chondrocytes in the hypertrophic zone to ensure accurate measurements, and the cells within S5-S6 were chosen because an adequate number of intact cells from these segments could consistently be observed.

\section{Measurement of cell shrinkage}

The accuracy of the method used for assessing chondrocyte shrinkage in histological sections as described in Materials \& Methods (Fig. 2A panel a) was initially determined by measuring the area of GPC cells that had distinct and welldefined perimeters. The cell measurement was made independently using the free-hand selection tool on the same cell twice and the difference between the two readings compared. The mean difference between the two measurements was $2.7 \pm 1.9 \%$ (mean \pm standard deviation (S.D.), for 11 cells) indicating the measurement method had an appropriate level of accuracy.

\section{Morphology of growth plate chondrocytes fixed using conventional solutions}

An ideal fixative should successfully preserve tissue for subsequent staining procedures, but it is important to accurately retain the original morphology of the living cells in the tissue, free from artefacts occurring during the fixation process. To demonstrate the morphology of GPC 

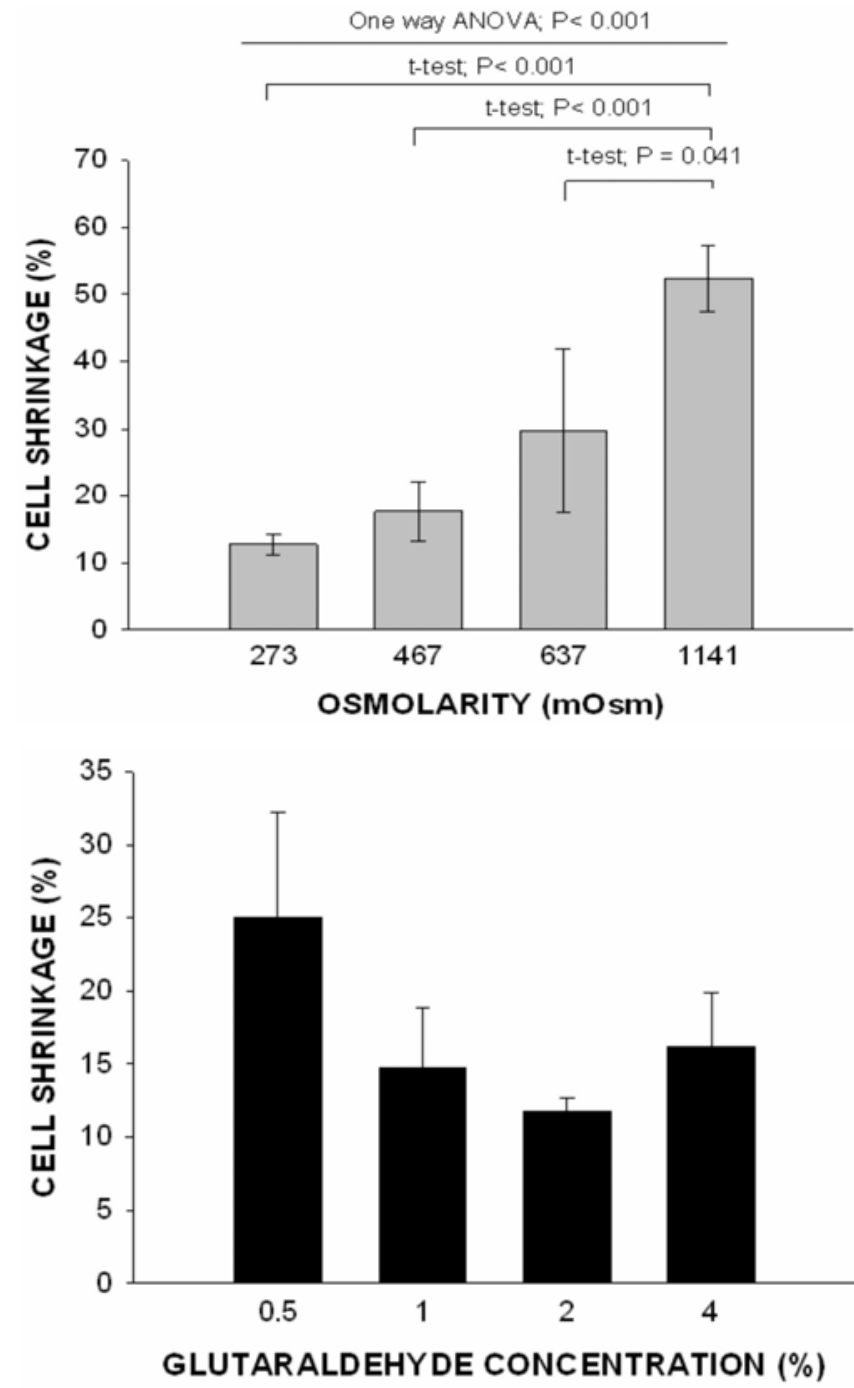

Fig. 4A. Chondrocyte shrinkage increased with elevated osmolarity of the fixative solution. Whole bones were fixed in solutions composed of $1 \% \mathrm{GA}$ and $0.7 \%$ RHT, with osmolarity varied over the range 273 to $1141 \mathrm{mOsm}$ by the addition of $\mathrm{NaCl}$ (see Table 2). Shrinkage of GPC was determined as described (see Materials and Methods, and Fig. 2A panel a). Data were from at least (3[44]) for each condition and are presented as means \pm S.E.M.

Fig. 4B. There was no difference in cell shrinkage with an increase of fixative concentration if osmolarity was kept constant. Whole bones were fixed in fixative solutions with the GA concentration varied over the range 0.5 to $4 \%$, but with the osmolarity maintained constant at $\sim 550$ mOsm (see Table 3 for composition of solutions). Shrinkage of GPC was determined as described (see Materials and Methods, and Fig. 2A panel a). There was no significant difference between any pairs of data (Student's unpaired $t$-test). Data were from at least (5[44]) for each condition and presented as means \pm S.E.M. fixed with conventional fixatives (Farnum et al., 2002; Hosoya et al., 2005; Hunziker et al., 1983), we used three standard and widely-used solutions (Table 1). These fixative solutions were all hyper-osmotic (Table 1), and therefore for comparison an iso-osmotic fixative with osmolarity adjusted to close to that of typical extracellular physiological solutions (280mOsm; Table 1), was also included.

In whole (non-bisected) bone samples, fixed and processed as described for histology (see Materials and Methods), there was a clear cell shrinkage artefact observed in tissue fixed with the three conventional fixatives (solutions A, B \& C; Table 1; Fig. 2A panels a-c)). Among the three fixatives, chondrocyte shrinkage assessed visually was most marked for solutions $\mathrm{A}$ and $\mathrm{B}$ and least for solution C (Fig. 2A(c)). When osmotically corrected solution D ( 280mOsm) was used, we observed no apparent cell shrinkage (Fig. 2A panel d). Quantitatively, solution A caused the highest cell shrinkage (44 $\pm 3 \%$ (3[44])), followed by tissue fixed in solution B (31 $\pm 4 \%$ (3[44]), then cells in solution C $17 \pm 5 \%(3[44])$ and finally for the osmotically-corrected fixative solution $\mathrm{D}$, there was no significant change in cell volume $(5.5 \pm 0.8 \%$ (3[44])). When analysing the extent of the shrinkage from solutions A to D (lowering osmolarity, Table 1), there was a significantly decreasing trend (one-way ANOVA test;
$P=0.010$ ) however only the shrinkage for cells in solutions A and B were significantly different (unpaired Student's $t$-test, $P<0.05$ ) from the osmotically-corrected fixative solution D. Note that although shrunken cells were routinely observed microscopically in cells fixed in solution C (Fig. 2A panel c) the pooled data did not show a significant difference and this was mainly because of the range in the magnitude of the shrinkage effect.

In bisected bones (Fig. 2B), microscopic inspection showed clearly that the extent of the chondrocyte shrinking artefact was considerably reduced with the four fixatives when compared to the cells within fixed whole bones (Fig. 2A panels a-d). When the shrinkage was quantified (Fig. $3 \mathrm{~B})$, the same decreasing trend in cell shrinkage with the four fixatives was also observed and the trend significant over the whole range (one-way ANOVA test; $P=0.024$ ). The absolute level of shrinkage and the trend with decreasing osmolarity, was less compared to the data for intact bones (Fig. 3A). When the data sets for intact and bisected bones over the range of fixatives were compared using a two-way ANOVA, the difference was significant $(P=0.004)$. In solution A cell shrinkage in bisected bones was $22 \pm 2.6 \%$, which was significantly less than the shrinkage of chondrocytes fixed in intact tibias $(P=0.030)$. Fixative solution B caused $17 \pm 1.4 \%$ (3[44]) shrinkage whereas solution $C$ caused $9 \pm 0.4 \%$ (3[44]) cell shrinkage 


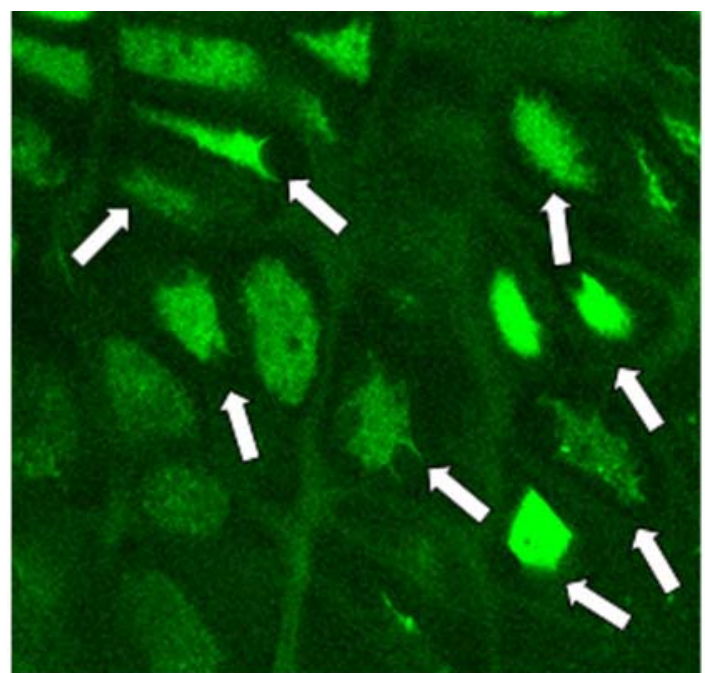

a. Fixed-intact bone (PFA $4 \%$ )

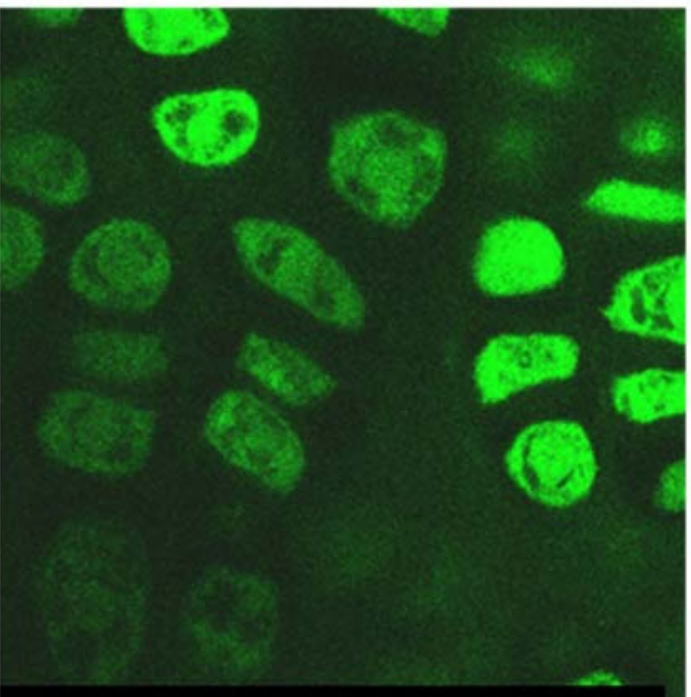

c. Fixed-bisected bone (GA $1.3 \%+0.5 \%$ RHT)
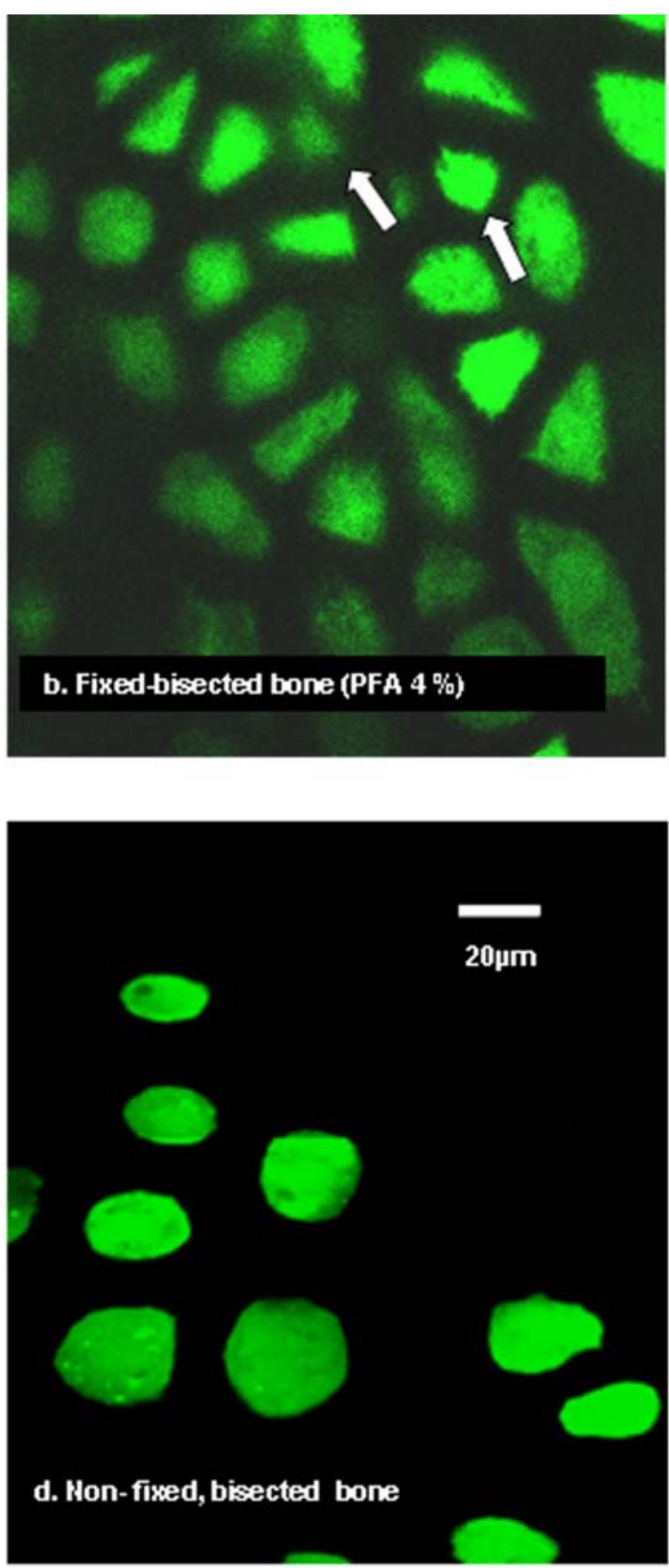

Fig. 5. Reduced volume and altered morphology of in situ GPC fixed within intact bone compared to those within bisected bones. Panels (a-c) showed the typical appearance of fluorescently (CMFDA-green)-labelled chondrocytes within intact (panel a) or bisected (panels b, c) bones, and fixed under the various conditions indicated. The shrinkage of some cells was observed in the fixed in situ cells (examples indicated with white arrows, panels a, b) but not in the osmotically-corrected fixative solution D (panel c). Panel (d) shows the appearance of unfixed (i.e., living) in situ hypertrophic GPCs labelled with calcein. All images were taken by CLSM using a x63 water-dipping objective. Cell volume measurements were performed as described (see Materials and Methods) with pooled data given in Table 4. Details of the composition of fixative solutions are given in Table 1 . Scale bar $=20 \mathrm{~mm}$.

and these values were less than for intact bones but did not reach the level of significance $(P>0.05)$. Cell shrinkage in the iso-osmotic fixative solution D for GPC in bisected bones was only $4 \pm 0.4 \%$ (3[44]; Fig. 3 ) and this was not significantly different from the data in intact bones (see above). These results showed that the shrinkage artefact was considerably reduced if the bones were bisected prior to fixation, and with osmotic correction, there was no significant shrinkage artefact of GPC in either intact or bisected bones.

As noted in Table 1, the $\mathrm{pH}$ of the fixatives varied over the range 5.67 to 7.11 , which was the result of different types and concentration of fixative agents and buffer concentration. We conducted a further experiment to examine whether $\mathrm{pH}$ contributed significantly to the quality of tissue preservation. We tested two $\mathrm{pH}$ values (i.e., 5.6 and 7.2) using the same fixative solution (solution D) to fix two groups of growth plate tissue from proximal tibia of $\mathrm{P} 7$ rats $(\mathrm{n}=3)$. Using the same method to quantify the cell shrinkage as described previously, the result showed that at $\mathrm{pH} 5.7$ there was $8 \pm 0.6 \%$ (mean \pm S.E.M.) cell shrinkage, whereas at $\mathrm{pH} 7.2$ there was $7 \pm 1.5 \%$ of cell shrinkage. These were not significantly different $(P<0.05)$ and so we concluded that $\mathrm{pH}$ over this range had a 
negligible effect on cell shrinkage compared to the osmolarity of the fixative solutions.

\section{Fixation of GPC using different concentrations and osmolarities of glutaraldehyde (GA) solution}

To test whether the osmolarity or concentration of fixative was responsible for the shrinkage artefact, whole bones were immersed in solutions with varying osmolarity (273$1141 \mathrm{mOsm}$ ) and standard fixative concentrations (GA 1\%, RHT $0.7 \%$; Table 2), or in solutions varying fixative concentration (GA $0.5-4 \%$ ) whilst maintaining osmolarity relatively constant $(555 \pm 8 \mathrm{mOsm}$; Table 3$)$. At the lowest osmolarity ( $273 \pm 13 \mathrm{mOsm})$, cell shrinkage was minimal $(13 \pm 0.6 \%(3[44]))$, but as it was raised, there was a progressive and significant increase (ANOVA, $P<0.001$ ) in the extent of cell shrinkage (Fig. 4(A)). At the highest osmolarity studied (1141mOsm) cell shrinkage was $52 \pm$ $1.6 \%$ (3[44]) and significantly greater (unpaired Student's t-test, $P<0.001$ for both) than the shrinkage observed in 273 and 467 mOsm solutions. When the GA concentration was varied over the range 0.5 to $4 \%$, but with the osmolarity of all solutions maintained constant, the shrinkage of GPC fixed in intact bones with $1 \%, 2 \%$ and $4 \%$ GA was $15 \pm$ $2.4 \%, 12 \pm 0.5 \%$, and $16 \pm 2.1 \%$ respectively, and not significantly different $(P>0.05$; data from at least (5[44]); Fig. 4B). It was notable that GA at $0.5 \%$ showed an apparent slightly higher cell shrinkage $(25 \pm 4.1 \%(5[44]))$ compared to $1 \%$ GA, but this was not significantly different from the lowest cell shrinkage produced by GA at $2 \%$ $(P>0.05)$. The morphology of a noticeable number of these cells was abnormal, suggesting that they were not properly fixed, and thus it was possible that the cells were susceptible to the post-fixation dehydration protocols (Mohamad Yusof Loqman, unpublished observations). Taken together, these data suggest that the shrinkage and morphological changes of GPC fixed using standard solutions could be accounted for by the osmolarity of the fixative solutions and not by the concentration of the fixative.

\section{In situ growth plate chondrocyte volume following} fixation with solution $A$ in intact and bisected bones The volume of in situ GPC within intact or sagittallybisected bones and fixed under various conditions was also assessed using another method. Solution A was chosen as it had the highest osmolarity among the different conventional fixative solutions used in the present study, resulted in the greatest shrinkage artefact (which was easily measured), and has been used previously in the study of growth plate chondrocytes (see Table 1). Images of fluorescently-labelled in situ chondrocytes taken by CLSM showed the majority of cells with abnormal shrunken morphology in intact bone fixed with this solution (Fig. 5a). When the bone was sagittally bisected and then fixed using the same solution, the proportion of shrunken chondrocytes was markedly less (Fig. 5b), and similarly when these bones were fixed in the osmotically-corrected solution (solution D, Table 1) there were almost no shrunken cells observed (Fig. 5c) with the cells appearing morphologically normal. The volume of GPC fixed in the intact bone had a significantly reduced cell volume of almost two and half-fold less compared to the cells in the bisected bone (Table 4; unpaired $t$-test: $P=0.016, \mathrm{n}=5$ ). For comparison, GPC volume of living non-fixed bone and of bisected bones fixed in solution $\mathrm{D}$ were not significantly different from the GPC volume of bisected bone fixed in solution A (unpaired $t$-tests, $P>0.05$ ). However, the volume of GPC fixed in solution A showed no significant decrease compared to the volume of GPCs fixed in solution D and non-fixed GPC as expected due to cell shrinkage, as shown previously (Figure 3B). The reason for this was not immediately obvious, although it should be noted that the errors associated with the measurement of in situ GPC volume were relatively large (Table 4). In summary, the reduction in cell volume was significantly greater for GPC within intact bones compared to bisected bones when fixed in a conventional fixative solution (Table 4).

\section{Discussion}

This study demonstrated that the osmolarity of fixative solutions was of critical importance for maintaining the normal morphology of in situ hypertrophic chondrocytes within the mammalian growth plate following chemical fixation. The shrinkage artefact evident when using conventional fixatives, was abolished when the osmolarity of the medium was reduced to close to that of normal physiological solutions or markedly reduced when the bones were sagittally bisected prior to fixation. These results raise important issues in relation to the accurate preservation of cell morphology by these widely-used chemical fixative solutions.

The first point to consider is the identification of a fixative concentration that ensured proper fixation of the

Table 4. Reduction of in situ GPC volume in fixed intact bones compared to bisected bones.

\begin{tabular}{|c|c|c|}
\hline $\begin{array}{c}\text { Nature of the } \\
\text { bone specimen }\end{array}$ & Fixatives & $\begin{array}{c}\text { In situ GPC } \\
\text { volume } \mathbf{( \mu m}^{\mathbf{3}} \text { ) }\end{array}$ \\
\hline Intact & PFA 4\% (solution A) & $1698 \pm 166^{*}$ \\
\hline Bisected & PFA 4\% ( solution A) & $4064 \pm 571$ \\
\hline Bisected & GA 1.3\% + RHT 0.5\% (solution D) & $3389 \pm 659$ \\
\hline Bisected & No fixative & $3411 \pm 1148$ \\
\hline
\end{tabular}

CMFDA-labelled in situ chondrocytes were fixed under the conditions shown (see Figure 5), their volume determined as described (see Materials and Methods) and the pooled data presented. Data (as means \pm S.E.M.) are from $n=5$ animals with 5-29 chondrocytes measured from each animal. *Denotes a significant difference $(P<0.05$; Student's unpaired $t$-test) between the data for the intact bone and each of the data sets for the bisected bone sections. 
cells/tissue without the osmolarity being too high to cause a shrinkage artefact and our data suggest that solution D was optimal (Table 1; Fig. 3). This osmolarity would be close to that normally present in physiological extracellular solutions meaning that the osmolarity of the cells within the extracellular matrix of the growth plate would similarly be optimal for normal chondrocyte morphology. (Note however that the exact extracellular osmolarity around the GPC will most likely be higher due to the presence of glycosaminoglycans present in the extracellular matrix (Urban et al., 1993)). A lower concentration of GA (0.5\%) produced what appeared to be a shrinkage artefact (Fig. 4B) but although individual shrunken cells were present on visual examination, statistical analysis of pooled data showed this was not significant. However we would caution against using such a low concentration as the fine appearance of the cells suggested that there were cells that were not properly fixed, resulting in morphological changes/distortions during post-fixation protocols (Mohamad Yusof Loqman, unpublished observations). Previous studies have, however, successfully utilized low fixative concentrations. For example Maunsbach (1966) investigating the kidney and Hopwood (1967) studying the brain noted that GA was an effective fixative down to $0.25 \%$ (Hopwood, 1967; Maunsbach, 1966). It is possible that low fixative concentrations could be used successfully in these studies because of the different physical nature of hard tissues compared to soft tissues, as in the latter the diffusion rate and thus penetration of the fixative would be expected to be considerably greater. Our findings were in general agreement with a previous report that identified the importance of fixative osmolarity to produce correct soft tissue preservation. Mathieu et al., (1978) reported both the GA percentage and molarity of the fixative vehicle were of importance for the preservation of lung tissue. In this study, they noted the shrinkage was induced by the osmolarity of buffer and fixative combined, as evidenced by shape changes of erythrocytes in capillaries and small vessels of the trachea, and a reduction in the air-blood tissue barrier of the trachea with different fixative osmolarities. Higher fixative concentrations (e.g. 2-4\% GA) could of course be used for some applications where cell shrinkage is not a concern (e.g. for tissue perfusion fixation (Santoreneos et al., 1998) or biomaterial fixation (Nuss et al., 2006)), but clearly the results from the present study emphasize the importance of researchers being aware of the potential for an osmotic shrinkage artefact to cell shape.

In the present study we included RHT (ruthenium hexamine trichloride) in most of the fixative solutions (Table 1). Hunziker et al., (1982) have proposed that this cationic dye stabilized the GPC plasma membrane within the lacuna by establishing electrostatic cross-linkage between anionic components within the plasma membrane and the proteoglycans of the pericellular matrix which surrounds chondrocytes. They suggested that this could prevent the rupture or detachment of the plasma membrane from the pericellular matrix when conventional aldehyde solutions were used simultaneously (Hunziker et al., 1982, 1992) (Fixative solutions B and C; Table 1). In our hands however, the presence of RHT could not prevent the shrinkage artefact (see Fig. 3). Thus, although the \% shrinkage was not significantly different from the osmotically-corrected fixative solution (solution D) it was still clearly greater than the solution B \& C. In addition, we routinely observed abnormal/shrunken cells (Fig. 2A panels $\mathrm{b}$ and c) as also observed in the original Hunziker et al. (1983) study. Therefore, although it is possible that RHT does protect against the shrinkage effect to some extent by stabilizing the cell membrane against the pericellular matrix, we feel that osmotic correction is the preferred procedure to eliminate the artefact (Fig. 3) and the presence of any abnormal cells (Fig. 2A panel d).

The nature of the chemical fixative is also an issue of importance as there is not one fixative suitable for all applications. For example, GA has been associated with antigen masking due to its excessive and aggressive crosslinking of proteins, and is therefore normally considered unsuitable for tissues intended for immunochemical staining (Renshaw, 2007). GA is usually used as a mixture with PFA termed Karnovsky's fixative (Karnovsky, 1965) so as to take advantage of the latter which has rapid tissue penetration although the fixation rate is not as rapid as that of GA (Kiernan, 1999). Our view is that PFA (4\%) alone, probably gives the best compromise between good cytological preservation and immunolocalization, while at the same time maintaining antigen masking to a minimum. However, as it is a fixative solution with high osmolarity (Table 1), tissues should be bisected beforehand to maximize rapid fixative access to limit undesirable cell shrinkage artefacts although it should be noted that they were still clearly apparent (Fig. 2B panel a) and still significant ( $20 \%$ shrinkage, Fig. 3 ). We note that although $10 \%$ neutral buffered formalin is rarely used in growth plate studies, it is a widely used fixative for routine histology and histopathology (Renshaw, 2007). However it should be noted that its osmolarity (measured at approx. 1700mOsm; Mohamad Yusof Loqman, unpublished observations) is even higher than the fixatives used here and thus we would expect that the artefactual shrinkage would be even more marked than reported for solution A (4\% PFA).

The finding that the shrinkage artefact was significantly reduced in bisected compared to whole bones, strongly suggested that the rate of penetration of the fixative compared to the osmotic changes to chondrocytes resulting from the high osmolarity of the fixative solutions are important. In the whole bone, the large shrinkage artefact suggested that osmotically-induced cell shrinkage occurred before the tissue was fixed. Thus when the bone was placed in the fixative solution, water movement out of the bones to the hyper-osmolar fixative solution occurred rapidly, and before the fixative fully penetrated the bone/cartilage matrix to fix the cells throughout the sample. Dempster (1960) has shown that fixatives obeyed the diffusion laws, that is, the depth penetrated (d) was proportional to the square root of time and the coefficient of diffusibility of the fixative, which was specific for each fixative. As the diffusion is directly proportional to the concentration gradient based on Fick's Law (Mehrer, 2007), the diffusibility of the fixative molecules (PFA, FA, GA) through the extracellular matrix of the tissue will undoubtedly be less than that for water molecules because 
of their different molecular shape and molecular weight. Thus, the diffusibility of the fixatives will be markedly less than that of water, leading to a greater shrinkage effect in thicker and denser tissues such as bone/cartilage, compared to 'soft' tissues such as brain and kidney. For thick tissues where preservation of cell morphology deep in the tissue is of importance, osmotic adjustment with lower fixation concentrations and longer fixation times would be advisable. Most workers set the fixation period using conventional fixatives of between 1- $4 \mathrm{hrs}$, or even longer (Hopwood, 1969). The optimum time will depend on several factors including the physical properties of the tissue (e.g. bone/cartilage vs. brain) concentration of the fixative and thickness of tissue sections. Higher fixative concentration requires shorter fixation times (Monis et al., 1965) whereas thicker blocks and harder tissues will necessitate longer fixation times as the penetration of the fixative will be slower.

Our results demonstrated that the shrinkage artefact could also be significantly reduced - although not abolished - when the bone was bisected before being fixed in standard (high osmolarity) fixative solutions (Fig. 3). Bone bisection would markedly reduce the physical obstacles and diffusional distances thereby providing a more direct and far more rapid exposure of the GPC that were being visualized to the fixative solutions. The rate of fixation would thus be much more rapid compared to GPC within intact bone, although the fact that the shrinkage artefact was still present indicated that despite the increased access provided to the fixative, significant cell shrinkage still occurred before the tissue was effectively fixed (Fig. $3)$. However, the drawback with bone bisection as a manoeuvre to reduce the fixation artefact would be that it could cause physical trauma/death to the cells at the cut edge (Huntley et al., 2005) and unless care was taken with imaging protocols by optically sectioning deeper into the tissue, the damaged surface cells would be the ones that are visualized. Bone bisection would also release internal (physiological) pressures within the bone and result in the loss/damage to matrix constituents (loss of proteoglycans, damage to the collagenous network, altered ionic/osmotic environment) potentially leading to changes to the in vivo properties (volume/morphology) of chondrocytes prior to fixation (Guilak and Mow, 2000).

Our measurements of cell shrinkage by a histological method (Fig. 2A,B; Fig. 3) were supported to some extent by volume analysis of fluorescently-labelled living in situ GPC images taken by CLSM (Fig.5 and Table 4). Although the latter technique was more time-consuming, it served as a useful additional and direct measure of cell volume to confirm the cell shrinkage due to hyper-osmolar fixatives. The results from this method clearly showed the reduction in the cell volume of chondrocytes fixed with PFA (4\%) in intact bone compared to bisected bone (Table 4). We would have expected that in parallel with the histological shrinkage measurements (Fig. 3A, B), the volume of cells within the bisected bone samples would not have been reduced in the PFA solution to the same extent as cells fixed with the osmotically-corrected fixative solution. At present we do not have an explanation for this finding, but note that we did not find the volume method was as sensitive for detecting the chondrocyte shrinkage compared to the histological method.

Both of these approaches provided us with more accurate quantitative measurements of the cell shrinkage artefact, compared to previous indirect methods e.g. counting the number of cell nuclei per unit area of tissue (Fox et al., 1985). Previous studies had suggested fixation artefacts arose from subsequent steps in tissue processing e.g. during ethanol-induced dehydration and embedding (Hopwood, 1969). However our data suggested that before it was possible to determine these secondary artefacts resulting from further preparation of tissue for histological analysis, it was essential that as far as possible the fixed tissue was close to its native state by abolishing the osmotic shrinkage artefact reported here.

In summary, our study demonstrated that the high osmolarity of conventional fixatives caused a shrinkage artefact to chondrocytes within the hypertrophic zone of the mammalian growth plate. This was particularly noticeable when whole bones were fixed, but was still present when the bones were bisected prior to fixation. This problem could be avoided by adjusting the osmolarity of the fixatives to the osmotic pressure of normal extracellular fluids ( $280 \mathrm{mOsm})$. In conclusion, in order to preserve the normal volume/morphology of cells within tissue samples, careful consideration should be given to the osmotic pressure of the fixative solution.

\section{Acknowledgements}

This work was supported by Universiti Putra Malaysia (UPM) and Ministry of Higher Education Malaysia under the SLAB scholarship (Scheme of Academic Training for Bumiputera) for Mohamad Yusof Loqman. Additional funding was provided by the Biotechnology and Biological Sciences Research Council (BB/C513985/1) and Wellcome Trust (075753/Z/04/Z). CF was supported by funding from the Institute Strategic Programme Grant from the Biotechnology and Biological Sciences Research Council, UK. We also thank Dr Michael Cousin for the donation of some biological samples.

\section{References}

Baker JK (1960) Cytological Technique: The Principles Underlying Routine Methods. Methuen, London.

Bancroft JD, Cook HC (1994) Manual of Histological Techniques and Their Diagnostic Application. Churchill Livingstone, Edinburgh.

Breur GJ, VanEnkevort BA, Farnum CE, Wilsman NJ (1991) Linear relationship between the volume of hypertrophic chondrocytes and the rate of longitudinal bone growth in growth plates. J Orthop Res 9: 348-359

Buckwalter JA, Mower D, Schafer J, Ungar R, Ginsberg B, Moore K (1985) Growth-plate-chondrocyte profiles and their orientation. J Bone Joint Surg [Am] 67A: 942-955. 
Buckwalter JA, Mower D, Ungar R, Schaeffer J, Ginsberg B (1986) Morphometric analysis of chondrocyte hypertrophy. J Bone Joint Surg [Am] 68A: 243-255.

Bush PG, Hall AC (2001) The osmotic sensitivity of isolated and in situ bovine articular chondrocytes. J Orthop Res 19: 768-778.

Bush PG, Wokosin DL, Hall AC (2007) Two-versus one photon excitation laser scanning microscopy: Critical importance of excitation wavelength. Front Biosci 12: 2646-2657.

Bush PG, Parisinos CA, Hall AC (2008) The osmotic sensitivity of in situ rat growth plate chondrocytes: clarifying the mechanism of hypertrophy. J Cell Physiol 214: 621-629.

Dempster WT (1960) Rates of penetration of fixing fluids. J Amer Anat 107: 59-72.

Erben RG (1997) Embedding of bone samples in methylmethacrylate: An improved method suitable for bone histomorphometry, histochemistry, and immunohistochemistry. J Histochem Cytochem 45: 307313.

Farnum CE, Lee R, O’Hara K, Urban JPG (2002) Volume increase in growth plate chondrocytes during hypertrophy: The contribution of organic osmolytes. Bone 30: $574-581$.

Farnum CE, Wilsman NJ (1986) In situ localization of lectin-binding glycoconjugates in the matrix of growthplate cartilage. Am J Anat 176: 65-82.

Fox CH, Johnson FB, Whiting J, Roller PP (1985) Formaldehyde fixation. J Histochem Cytochem 33: 845853.

Guilak F, Mow VC (2000) The mechanical environment of the chondrocyte: A biphasic finite element model of cell-matrix interactions in articular cartilage. J Biomech 33: 1663-1673.

Hopwood D (1967) The behaviour of various glutaraldehydes on Sephadex G-10 and some implications for fixation. Histochemie 11: 289-295.

Hopwood D (1969) Fixatives and fixation: a review. Histochem J 1: 323-360.

Hopwood D (1985) Cells and tissue fixation 1972 1982. Histochem J 17: 389-442.

Hosoya A, Hoshi K, Sahara N, Ninomiya T, Akahane S, Kawamoto T, Ozawa H (2005) Effects of fixation and decalcification on the immunohistochemical localization of bone matrix proteins in fresh-frozen bone sections. Histochem Cell Biol 123: 639-646.

Huntley JS, Bush PG, McBirnie JM, Simpson AH, Hall AC (2005) Chondrocyte death associated with human femoral osteochondral harvest as performed for mosaicplasty. J Bone Joint Surg [Am] 87A: 351-360.

Hunziker EB, Herrmann W, Schenck RK (1982) Improved cartilage fixation by ruthenium trichloride (RHT). A prerequisite for morphometry in growth cartilage. J Ultrstruct Res 81: 1-12.

Hunziker EB, Herrmann W, Schenk RK (1983) Ruthenium hexamine trichloride (RHT)-mediated interaction between plasmalemmal components and pericellular matrix proteoglycans is responsible for the preservation of chondrocytic plasma membranes in situ during cartilage fixation. J Histochem Cytochem 31: 717727.

Hunziker EB, Ludi A, Hermann W (1992) Preservation of cartilage matrix proteoglycans using cationic dyes chemically related to ruthenium hexamine trichloride. J Histochem Cytochem 40: 909-917.

Karnovsky MJ (1965) A formaldehyde-glutaraldehyde fixative of high osmolality for use in electron microscopy. J Cell Biol 27: 137A-138A.

Kiernan JA (1999) Histological and Histochemical Methods: Theory and Practice. Butterworth-Heinemann, Oxford.

Kouri JB, Jimenez SA, Quintero M, Chico A (1996) Ultrastructural study of chondrocytes from fibrillated and non-fibrillated human osteoarthritic cartilage. Osteoarthr Cartil 4: 111-125.

Lee K, Lanske B, Karaplis AC, Deeds JD, Kohno H, Nissenson RA, Kronenberg HM, Segre GV (1996) Parathyroid hormone-related peptide delays terminal differentiation of chondrocytes during endochondral bone development. Endocrinology 137: 5109-5118

Mathieu O, Claassen H, Weibel ER (1978) Differential effect of glutaraldehyde and buffer osmolarity on cell dimensions: A study on lung tissue. J Ultrastruct Res 63: 20-34.

Maunsbach AB (1966) The influence of different fixatives and fixation methods on the ultrastructure of rat kidney proximal tubule. II. Effects of varying osmolality ionic strength, buffer system and fixative concentration of glutaraldehyde solutions. J Ultrastruct Res 15: 283-309.

Mehrer H (2007) Diffusion in Solids: Fundamentals, Methods, Materials, Diffusion-Controlled Process. Springer, Berlin-London.

Monis B, Wasserkrug H, Seligman AM (1965) Comparison of fixatives and substrates for aminopeptidase. J Histochem Cytochem 13: 503-509.

Nuss KMR, Auer JA, Alois Boos A, Rechenberg BV (2006) An animal model in sheep for biocompatibility testing of biomaterials in cancellous bones. BMC Musculoskelet Disord 7: 67.

Renshaw S (2007) Immunochemical staining. In Renshaw S (ed). Immunohistochemistry. Scion Publishing Limited, Oxfordshire. pp 45-56.

Ross MH, Reith EJ (1985) Histology: A Text and Atlas. Harper \& Row Publishers, JB Lippincott Company, New York.

Sanchez CP, Kuizon BD, Abdella PA, Juppner H, Salusky IB, Goodman WG (2000) Impaired growth, delayed ossification, and reduced osteoclastic activity in the growth plate of calcium-supplemented rats with renal failure. Endocrinology 141:1536-1544.

Santoreneos S, Stoodley MA, Jones NR, Brown CJ (1998). A technique for in vivo vascular perfusion fixation of the sheep central nervous system. J Neurosci Meth 79: 195-199.

Schultz RL, Karlsson U (1965) Fixation of the central nervous system for electron microscopy by aldehyde perfusion. II Effect of osmolarity, $\mathrm{pH}$ of perfusate and fixative concentration. J Ultrastr Res 12: 187-206. 
Urban JPG, Hall AC, Gehl KA (1993) Regulation of matrix synthesis rates by the ionic and osmotic environment of articular chondrocytes. J Cell Physiol 154: 262-270.

Van der Eerden BCJ, Karperien M, Gevers EF, Lowik CWGM, Wit JA (2000) Expression of Indian Hedgehog, parathyroid hormone-related protein, and their receptors in the postnatal growth plate of the rat: evidence for a locally acting growth restraining feedback loop after birth. J Bone Miner Res 15: 1045-1055.

\section{Discussion with Reviewer}

Reviewer I: $10 \%$ Neutral Buffered Formalin is probably the most widely used fixative for routine histology and histopathology. Was this fixative tested at all? Did the authors simply concentrate on fixatives considered specific for growth plates?

Authors: While 10\% Neutral Buffered Formalin (also referred to as $4 \%$ formaldehyde (Renshaw, 2007)) is widely used for processing tissues for routine histology, its use in growth plate tissue fixation is rather uncommon compared to other conventional fixatives as tested in the present study. Accordingly we have not focussed on this fixative. We note that the osmolarity of the $10 \%$ neutral phosphate buffered formaldehyde solution measured in our laboratory was $\sim 1700 \mathrm{mOsm}$, and thus much higher than the osmolarity of the fixatives used in the present investigation. We would expect that the artefactual shrinkage produced by this fixative would be much more marked, and have included a comment on the use of this commonly used fixative compared to the other fixatives used in our study. 